\title{
Hipertextos digitales como material de enseñanza para el estudio previo sobre la metodología de aula invertida: percepciones de académicos de salud
}

\author{
Camila Maria Bandeira Scheunemann ${ }^{1}$ \\ camila.b91@hotmail.com \\ http://orcid.org/0000-0003-1658-6520 \\ Caroline Medeiros Martins de Almeida ${ }^{2}$ \\ carolinemalmeida@unisinos.br \\ https://orcid.org/0000-0002-0445-5921 \\ ${ }^{1}$ Universidade Luterana do Brasil (ULBRA, Brasil) \\ ${ }^{2}$ Universidade do Vale do Rio dos Sinos (UNISINOS, Brasil)
}

Recibido: 14/05/2020 Aceptado: 29/07/2020

\begin{abstract}
Resumen
Las transformaciones que han tenido lugar en la enseñanza han impactado las prácticas y metodologías pedagógicas, siendo una de ellas el aula invertida. Uno de los momentos de esta metodología es la clase previa, para lo cual es necesaria la preparación de materiales didácticos. Este estudio de caso cuantitativo-cualitativo tuvo como objetivo investigar las percepciones de los académicos de la salud sobre el uso de hipertextos digitales como material de estudio previo en el aula invertida y sugerirlos como una posibilidad para material didáctico previo. Los participantes eran estudiantes de anatomía humana de una universidad en la región metropolitana de Porto Alegre/RS. Se llevaron a cabo seis clases invertidas, para las cuales se prepararon hipertextos digitales para estudio previo. Los datos se recopilaron a través de un cuestionario adjunto a cada hipertexto proporcionado y las preguntas se analizaron a través de las puntuaciones de las respuestas y el análisis de contenido. Los resultados apuntaron a un mayor acceso a hipertextos digitales por teléfono celular, con dificultades principalmente en las primeras clases, en aspectos técnicos y didácticos; los hipertextos digitales se consideraron adecuados porque son completos y fáciles de entender, y el elemento constitutivo que más ayudó fueron los textos.
\end{abstract}

Palabras clave: Aula invertida; Pre-clase; Estudio previo; Hipertexto digital; Material didáctico.

\section{Hipertextos digitais como material didático para estudo prévio na metodologia da sala de aula invertida: percepções de acadêmicos da área da saúde}

\begin{abstract}
Resumo
As transformações que vêm ocorrendo no ensino têm impactado as práticas pedagógicas e metodologias, sendo uma delas a sala de aula invertida. Um dos momentos desta metodologia é a pré-aula, para a qual é necessário a elaboração de materiais didáticos. Este estudo de caso, de natureza quantitativa-qualitativa, teve como objetivo investigar as percepções de acadêmicos da área da saúde sobre a utilização de hipertextos digitais como material de estudo prévio na sala de aula invertida e sugeri-los como possibilidade de material didático prévio. Os participantes foram acadêmicos de anatomia humana de uma universidade da região metropolitana de Porto Alegre/RS. Foram realizadas seis aulas invertidas, para as quais foram elaborados hipertextos digitais para estudo prévio. Os dados
\end{abstract}


foram coletados por um questionário em anexo a cada hipertexto disponibilizado e as questões foram analisadas através dos escores das respostas e da análise de conteúdo. Os resultados apontaram para maior acesso aos hipertextos digitais por telefone celular, com dificuldades principalmente nas primeiras aulas, em aspectos técnicos e didáticos; os hipertextos digitais foram considerados adequados por serem completos e de fácil entendimento, e o seu item constituinte que mais auxiliou foram os textos.

Palavras-chave: Sala de aula invertida; Pré-aula; Estudo prévio; Hipertexto digital; Material didático.

\title{
Digital hypertexts as a teaching material for prior study on flipped classroom methodology: perceptions of health area academics
}

\begin{abstract}
The transformations that have been occurring in teaching have impacted pedagogical practices and methodologies, one of which is the flipped classroom. One of the moments of this methodology is the pre-class, for which the preparation of teaching materials is necessary. This quantitative-qualitative case study aimed to investigate the perceptions of health academics about the use of digital hypertexts as prior study material in the flipped classroom and to suggest them as a possibility for prior didactic material. The participants were human anatomy students from a university in the metropolitan region of Porto Alegre/RS. Six flipped classes were held, for which digital hypertexts were prepared for prior study. The data were collected through a questionnaire attached to each hypertext provided and the questions were analyzed through the scores of the responses and content analysis. The results pointed to greater access to digital hypertexts by cell phone, with difficulties mainly in the first classes, in technical and didactic aspects; digital hypertexts were considered adequate because they are complete and easy to understand, and the constituent item that helped most was texts.
\end{abstract}

Keywords: Flipped Classroom; Pre-class; Previous study; Digital hypertext; Courseware.

\section{Introdução}

As transformações que vêm ocorrendo no ensino têm impactado as práticas pedagógicas e metodologias empregadas por docentes, buscando investigar as diferentes potencialidades de estratégias que podem ser desenvolvidas em prol de um ensino mais condizente com as necessidades contemporâneas.

Uma destas metodologias que vêm sendo foco crescente de pesquisas é a sala de aula invertida (SAI). Para Bergmann e Sams (2018, p. 11), na SAI "o que tradicionalmente é feito em sala de aula, agora é executado em casa, e o que tradicionalmente é feito como trabalho de casa, agora é realizado em sala de aula". Portanto, consiste em uma modalidade de e-learning na qual o conteúdo é estudado pelos alunos antes da aula presencial, de forma online, enquanto no tempo presencial são realizadas atividades de aplicação destes 
conhecimentos adquiridos no estudo prévio, por meio de diferenciadas possibilidades didáticas (Valente, 2014).

Para Talbert (2019), a aprendizagem invertida é uma abordagem pedagógica que proporciona ao aluno um primeiro contato com conceitos novos no espaço individual, por meio de uma atividade estruturada; já no espaço grupal são privilegiadas aprendizagens dinâmicas e interativas, nas quais os estudantes aplicam os conceitos aprendidos, sob orientação do professor.

Um dos momentos importantes da SAI é a realização do estudo prévio, ou seja, o trabalho realizado pelos alunos antes da aula presencial, no qual estudam o material fornecido pelo professor a fim de, posteriormente, na aula presencial, aplicar os conhecimentos adquiridos por meio destes materiais em prol de sua utilização nas atividades de aplicação.

Em função da necessidade de suporte para estas tarefas prévias, diversos materiais e atividades passaram a ser elaborados e discutidos, a fim de investigar as melhores escolhas didáticas para o modelo da SAI, que podem variar conforme a disciplina em questão (Sánchez-Rodrigues et al., 2017).

Na metodologia da SAI, os procedimentos adotados para a aprendizagem pré-aula podem desempenhar um papel diferencial em sua eficácia; ainda são incipientes e necessárias pesquisas sobre quando, como e por que os alunos se envolvem profundamente com o conteúdo fora da aula para o sucesso da aprendizagem inversa. Existem poucas pesquisas sobre como fornecer a instrução prévia, isto é, estão faltando estudos empíricos para investigar esse aspecto, pois a falta de clareza sobre a melhor disponibilidade de conteúdo na pré-aula pode ser uma razão para os professores hesitarem em adotar a metodologia (Jensen et al., 2018).

Uma questão a ser investigada, neste sentido, é referente aos materiais que o professor disponibiliza para o estudo prévio; a sugestão mais indicada é que os docentes optem por elaborar o material, que pode variar de acordo com sua escolha. A maioria dos estudos de SAI utiliza como formato principal de material prévio as videoaulas; no entanto, Bergmann e Sams (2018, p. 89), pioneiros na utilização da metodologia, reforçam que "nem todas as salas de aula invertidas usam vídeos como ferramenta instrucional". Frisam, ainda, que o aspecto mais essencial em um ambiente de aprendizado invertido é o uso eficaz do tempo presencial, que ocorre graças a ampliação deste tempo, devido à aula 
prévia, e que esta metodologia deve ser estudada profundamente (Bergmann, 2018; Bergmann \& Sams, 2014).

Neste estudo, que faz parte de uma pesquisa de doutorado em andamento, optou-se por utilizar hipertextos digitais como materiais prévios fornecidos para os alunos estudarem na pré-aula, na disciplina de anatomia humana. Carvalho et al. (2012) apontam que no ensino de anatomia humana, que enfrenta uma realidade de escassez de recursos cadavéricos, o meio digital apresenta-se como uma alternativa significativa para a realização de estudos.

Ao desenvolver aulas invertidas no ensino superior, na disciplina de anatomia humana, e elaborar materiais para estudo prévio em forma de hipertextos digitais, a pergunta que buscou-se responder foi: quais as percepções de acadêmicos da área da saúde sobre hipertextos digitais como material de estudo prévio na metodologia da sala de aula invertida?

Esta pesquisa teve como objetivo investigar as percepções de acadêmicos da área da saúde sobre a utilização de hipertextos digitais como material de estudo prévio na sala de aula invertida e sugeri-los como possibilidade de material didático prévio para esta metodologia.

\section{Sala de aula invertida}

Valente (2018) relata que a SAI tem sido uma metodologia implantada em universidades de renome, como a Harvard University e o Massachusetts Institute of Technology, que a inseriram em seus sistemas de ensino, adequando-os para que possam explorar os avanços das tecnologias, minimizando a evasão e a reprovação.

$\mathrm{Na}$ abordagem da SAI, o aluno estuda antes o conteúdo online e a aula se torna o lugar de aprendizagem ativa, onde há perguntas, discussões e atividades práticas; desta forma, o tempo em sala de aula é utilizado para a realização de projetos, inquirições, debates, ou tarefas de aplicação do conteúdo, envolvendo os alunos em processos cognitivos mais complexos (Bergmann, 2018; Valente, 2018). Ainda, para Valente (2018), o tipo de material ou atividades que o aluno realiza online e na sala de aula variam de acordo com a proposta que está sendo implantada, oportunizando diferentes possibilidades.

Talbert (2019) esclarece que o termo invertida se refere à inversão das atividades desenvolvidas por meio desta abordagem, abrangendo não apenas o que os alunos 
aprendem, mas também, como. Para o autor, os componentes tempo, espaço e atividade são essenciais e conferem ao modelo as suas peculiaridades mais importantes.

Valente (2018), baseado no relatório Flipped Classroom Field Guide, citou quatro regras básicas para inverter a sala de aula: I) os alunos são incentivados a participar tanto das atividades online quanto das presenciais, pois elas são computadas na sua avaliação formal; II) todos os materiais utilizados em sala de aula ou online devem ser altamente estruturados e bem planejados; III) em sala de aula as atividades devem conter atividades de aprendizagem ativa como questionamentos e resolução de problemas, incentivando o estudante a recuperar, aplicar e ampliar o material aprendido online, IV) o feedback para os discentes deve ocorrer imediatamente após a realização das atividades presenciais.

$\mathrm{Na}$ sala de aula invertida os papéis dos alunos e dos professores também são alterados, fazendo com que os discentes sejam protagonistas de sua aprendizagem, e os docentes os mediadores deste processo. Para Bergmann e Sams (2012), o professor fica presente para auxiliar aos estudantes, esclarecendo dúvidas e corrigindo os erros, pois neste momento sua função em sala de aula é ampará-los e não mais transmitir informações, apenas.

De acordo com Conserva e Costa (2020), a SAI intenciona uma mudança paradigmática pelas transformações que oportuniza na sua forma organizacional e traz potencialidades na otimização do tempo presencial, interatividade discente, reestruturação das práticas pedagógicas, papel ativo e responsabilização da aprendizagem pelos estudantes.

\section{Pré-aula e materiais de pré-aula}

O contato dos alunos com o material pré-aula possibilita trabalhar em seu próprio ritmo, incentivando-os a preparar-se para o encontro presencial. Se esta etapa for eficaz, pode ajudá-los a perceber quais são os principais conceitos a serem revistos e suas dúvidas, o que fornece suporte para um melhor aproveitamento na etapa presencial (Valente, 2014).

O deslocamento da instrução direta do espaço grupal para o individual, possibilitado pela SAI, pretende fazer deste momento uma oportunidade de preparar os discentes para participarem de forma ativa e produtiva posteriormente, no espaço grupal; para que seja efetivo é necessário, entretanto, que os alunos aprendam o suficiente no 
momento individual (antes da aula), para que sejam produtivos quando chegarem no espaço grupal (Talbert, 2019).

Para o estudo prévio, a produção de materiais pelo docente se apresenta como uma característica importante na metodologia da SAI. Entre as estratégias online, videoaulas gravadas pelo professor apresentam-se como a mais comumente utilizada; porém, é preciso observar a quantidade e tamanho dos vídeos, pois o objetivo da metodologia não é transformar em vídeo uma aula expositiva (Valente, 2014).

De acordo com a proposta de cada disciplina o material fornecido pode variar, ampliando as possibilidades de práticas diversificadas. Em função da disponibilidade prévia os estudantes podem acessar e estudar o material quantas vezes for necessário antes do encontro presencial (Sánchez-Rodríguez et al., 2017; Valente, 2014).

Além de vídeos, outros materiais podem oferecer suporte prévio, a partir das tecnologias digitais, as quais têm se mostrado como aliadas desta metodologia; dessa forma, o estudo prévio não está condicionado a assistir aulas expositivas em vídeo ou realizar leituras. Múltiplas ferramentas foram produzidas para disponibilizar os conteúdos, como softwares e demais recursos relacionados com mídias e plataformas virtuais (Talbert, 2019; Valério \& Moreira, 2018).

Apesar de os vídeos ainda serem o suporte virtual mais usual para a realização da pré-aula é fundamental que o professor conheça e possa utilizar outras possibilidades, tendo por base as tecnologias digitais, considerando opções como animações, simulações e laboratórios virtuais. O uso de diferentes materiais navegáveis como estes auxilia os alunos no aprofundamento dos seus conhecimentos (Valente, 2014).

Um papel de destaque atribuído ao professor na SAI é de que ele consiga mobilizar os alunos para que realizem o estudo prévio, motivando-os e comprometendo-os para esta finalidade, fator que determinará, em parte, o sucesso deste formato de aula. Para que esta tarefa seja exitosa, o docente pode lançar mão de artifícios como a sensibilização da turma para o tema e a conscientização da importância dessa ação para seu bom desempenho, além de esclarecer como a metodologia funciona (Martin et al., 2018; Valente, 2014).

É essencial que os discentes encontrem motivos que os levem a se comprometerem com o estudo prévio. Nesse contexto, o professor precisa demonstrar as vantagens do estudo preparatório e reconhecer o esforço daqueles alunos que o fazem, oferecendo feedback de suas dúvidas e colocações (Martin et al., 2018; Pavanelo \& Lima, 2017). 
O docente precisa estar atento, também, quanto à qualidade do material que irá disponibilizar, pois isso pode influenciar na motivação dos alunos frente ao estudo prévio e autonomia em sala de aula (González-Gómez et al., 2017). A adequação dos materiais pode exercer carga extra de trabalho aos docentes, pois requer muito tempo e, por isso, deve ser assumido de forma colaborativa entre os que aderirem à inversão (Yang, 2017).

Talbert (2019) discute a organização das atividades/materiais do espaço individual (ou pré-aula), e menciona a importância de um equilíbrio, pois elas não podem ser excessivas, num nível difícil, nem muito fáceis ou simples. Nesta perspectiva, menciona aspectos a serem observados sobre estas tarefas, como serem mínimas (solicitar o necessário para os objetivos de aprendizagem que os preparem para a atividade presencial), simples (claras e de fácil compreensão), envolventes (que despertem interesse), produtivas (prepare-os para atividades mais desafiadoras) e tolerante com os erros (erros como parte do processo de aprendizagem).

Jensen et al. (2018) aplicaram uma pesquisa em duas instituições de ensino, uma pública e outra privada, em aulas de Biologia nos Estados Unidos, com o objetivo de pesquisar três modalidades de conteúdo pré-aula (tutoriais interativos online, palestras em vídeo não interativas e leitura em estilo de livro didático). Os resultados demonstraram que as palestras em vídeo ofereceram uma pequena vantagem para a aprendizagem geral dos alunos; ambas populações demonstraram maior ganho de aprendizagem depois de palestras em vídeo, o que se deve, segundo os autores, ao fator agente pedagógico na tela, ou seja, o fato de o professor aparecer em vídeo explicando os conteúdos gera uma combinação de fatores, como a fala, a voz e as expressões faciais, que pode influenciar a eficácia das palestras em vídeo.

Na pesquisa de González-Gómez et al. (2017) os alunos destacaram que ter posse do material antes da aula ajuda a alcançar os objetivos de aprendizagem e completar com maior segurança as atividades de sala de aula. No estudo de Yang (2017), os participantes expuseram que leituras foram mais eficientes do que vídeos, isso por causa de sua duração e apresentação, que não foram adequadas, o que expressa o impacto da elaboração ineficiente dos materiais.

Explorando a inversão, Martin et al. (2018) analisaram os procedimentos e resultados obtidos com a aula inversa 'just in time teaching', buscando saber o que os alunos não conseguem entender nos materiais prévios fornecidos, por meio de uma 
estratégia para obtenção de informações após o estudo prévio. Para isso, aplicaram um questionário em anexo ao material de estudo prévio, com recolhimento de respostas online logo após a interação dos alunos com o material. De posse destas respostas, o professor às classificava e fornecia diferentes feedbacks, como retorno por e-mail (se a pergunta fosse urgente) e categorização das demais dúvidas com o uso de cores, conforme a pergunta seria utilizada para tarefas na atividade presencial.

Ribeirinha e Silva (2020) investigaram o componente online (pré-aula) em uma estratégia de SAI, em uma turma de ensino secundário em Portugal, onde os materiais de estudo prévio foram disponibilizados através da plataforma Edmodo, cerca de 72 horas antes da aula presencial, e incluíram vídeo, tomadas de nota, atividades reflexivas, e realização de um quiz. Segundo as percepções dos alunos, 81,8\% concorda totalmente ou parcialmente que os vídeos contribuíram para o interesse, e mostraram-se satisfeitos em realizar a preparação prévia online; já no quesito responsabilização pela aprendizagem, a porcentagem de concordância foi menor, com $63,6 \%$.

Na SAI é indispensável atenção e cuidado com os materiais, pois sempre que se dispõe a implementar uma estratégia diferente é preciso assegurar que eles sejam organizados para fornecer suporte adequado (Sommer \& Ritzhaupt, 2018).

\section{Hipertexto digital como material didático}

A leitura na contemporaneidade apresenta mudanças pois, apesar da ênfase no texto impresso, as pessoas utilizam outras maneiras para ler, em função das tecnologias de informação e comunicação e seus recursos, como aparelhos eletrônicos (tablets, smartphones, etc.), fazendo com que a leitura em suportes diferentes do impresso venha crescentemente se estabelecendo no cotidiano; uma destas formas textuais contemporâneas é representada pelos hipertextos digitais (Júnior \& Martins, 2019).

O hipertexto é "uma forma de escrita/leitura não-linear e não hierarquizada que permite o acesso ilimitado a blocos de informações ligados a palavras, partes de um texto ou imagens" (Santos et al., 2019, p. 794). Constitui-se, assim, em um texto característico do ciberespaço, que apresenta características mais dinâmicas e menos fixas do que os textos impressos, que permitem ao leitor escolher o caminho a ser percorrido, com linguagem e comunicação multimodal (Santos et al., 2019). 
O hipertexto permite acesso a diversas janelas e informações alcançáveis, fato que não ocorre em outros tipos de leituras, caracterizando-se como uma marca dos textos digitais. O design hipertextual possibilita a organização de pensamento de forma multidimensional (Santana \& Aragão, 2013).

Os hipertextos digitais apresentam como uma de suas características marcantes a navegação por meio de links, que conectam vários textos, possibilitando a construção de uma ponte entre um e outro, de forma complementar; isso requer uma transformação na prática da leitura, que pode ampliar os horizontes de um texto. Este tipo de leitura requer habilidades e atitudes diferentes do que a de um texto impresso e não se apresenta como uma tarefa simples, dependendo do caso, podendo levar à dispersão, como consequência da variedade de informações evidenciadas (Júnior \& Martins, 2019).

Os elementos que constituem um hipertexto remetem-se uns aos outros, criando um diálogo, ampliado o campo semântico e componentes como links, vídeos e outras formas de informação, exigindo um leitor ativo e facilitando-lhe a recuperação de informações de maneira instantânea (Santos et al., 2019).

O hipertexto é um material completo, pois inclui imagem, texto, vídeo e links, integrando diversas mídias, que separadas não teriam este sentido de completude, podendo apresentar o tema de estudo de várias formas. Levy (1993) relaciona esta combinação de mídias com uma característica dos hipertextos digitais, que é a multimodalidade, que proporciona uma organização em rede.

Os hipertextos digitais podem se constituir em material didático eficaz para a aprendizagem dos estudantes, sendo observado como um recurso propício para ser considerado pelos docentes na construção de seus materiais para os discentes. Podem ser vistos, nesta perspectiva, como uma forma de organizar as informações que permite uma maior dinamicidade quando comparado aos materiais impressos (Bandeira-Scheunemann \& Lopes, 2018).

A utilização de hipertextos digitais como finalidade pedagógica deve levar em conta sua adequada estruturação e planejamento, sempre considerando a capacidade cognitiva dos alunos e constitui-se adequado, pois vem ao encontro da capacidade multitarefa dos jovens inseridos na era digital (Santos et al., 2019). 


\section{Metodologia}

\section{Caracterização da pesquisa}

A pesquisa trata-se de um estudo de caso, método capaz de apreender o suficiente sobre o caso para absorver os significados complexos de um fenômeno específico (Godoy, 2006; Stake, 2000). Segundo Fonseca (2002, p. 33), "visa conhecer em profundidade o como e o porquê de uma determinada situação que se supõe ser única em muitos aspectos, procurando descobrir o que há nela de mais essencial e característico". Neste procedimento, o pesquisador não intervém na pesquisa, mas a relata tal como ele a percebe.

Ainda, caracteriza-se como de natureza quantitativa-qualitativa, tipo de estudo que permite uma melhor interpretação de fenômenos, de forma especial ao agregar a percepção dos indivíduos participantes da pesquisa; combinados, a utilização dos métodos quantitativos e qualitativos evitam as fragilidades próprias de cada um deles (Kirschbaum, 2013).

Este artigo faz parte de uma pesquisa de doutorado em andamento, aprovada pelo Comitê de Ética em Pesquisa em Seres Humanos da universidade vinculada, sob o número CAEE 00134418.0.0000.5349, que teve início no ano de 2018.

\section{Participantes}

Os participantes foram duas turmas de acadêmicos da disciplina de anatomia humana de cursos da área da saúde de uma universidade privada da região metropolitana de Porto Alegre (RS), sendo uma do primeiro semestre de 2019 e outra do segundo semestre de 2019. O número de alunos participantes das aulas invertidas variou e considera-se, para este artigo, a quantidade de respondentes aos questionários prévios, tendo em vista que em todas as aulas invertidas houve uma porcentagem de alunos que não responderam ao questionário de pré-aula, o qual originou os dados deste estudo. Desta forma, o número de participantes respondentes foram: aula invertida 1 (10 respondentes), aula invertida 2 (18 respondentes), aula invertida 3 (11 respondentes), aula invertida 4 (16 respondentes), aula invertida 5 (21 respondentes), aula invertida 6 (16 respondentes). 


\section{Prática pedagógica por meio de aulas invertidas}

Foram realizadas seis aulas invertidas, sendo três no primeiro e três no segundo semestre de 2019. As três aulas invertidas de cada turma foram intercaladas com aulas expositivas/tradicionais e aulas práticas. Para cada aula invertida foi disponibilizado material de estudo prévio, sendo um hipertexto digital para cada uma delas, postado com antecedência de uma semana à aula presencial, que era semanal; a postagem do material ocorreu na plataforma da instituição, em forma de estudo dirigido, que continha o link de acesso para o hipertexto digital e instruções de como os alunos deveriam realizar o referido estudo.

\section{Elaboração dos materiais de estudo prévio (hipertextos digitais)}

Como material de estudo prévio para as pré-aulas foram elaborados hipertextos digitais, construídos na Plataforma Wix e que se referiam às temáticas: (i) sistema muscular, (ii) sistema circulatório, (iii) sistema respiratório e (iv) sistema urinário e sistema genital. No primeiro semestre de aplicação a aula invertida 1 foi referente ao sistema muscular, a aula invertida 2 ao sistema circulatório e a aula invertida 3 aos sistemas urinário e genital; no segundo semestre, a aula invertida 1 foi referente ao sistema circulatório, a aula invertida 2 ao sistema respiratório e a aula invertida 3 aos sistemas urinário e genital; a escolha das temáticas foi feita de forma aleatória e conforme combinado com o professor titular da disciplina. A Figura 1 exemplifica o design de cada um dos hipertextos digitais elaborados, apresentando uma captura de tela de cada uma das páginas iniciais.

Figura 1: Design da página inicial dos hipertextos digitais elaborados para as pré-aulas

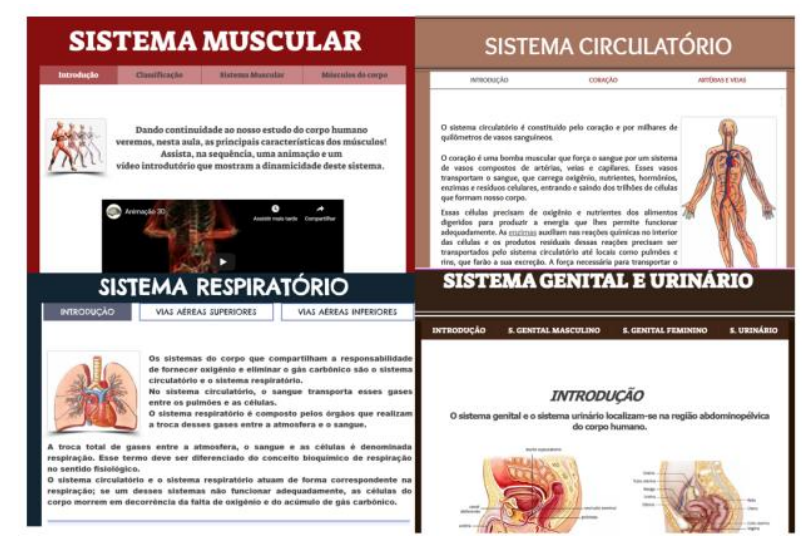

Fonte: Os autores (2020)

Disponível em: Sistema Muscular <https://camilab91.wixsite.com/meusite-1 $>$.

Sistema Circulatório: 〈https://camilab91.wixsite.com/sistemacirculatorio $>$.

Sistema Respiratório: 〈https://camilab91.wixsite.com/sistemarespiratorio>. 
Sistema Urinário e Sistema Genital: 〈https://camilab91.wixsite.com/sistemareprodutivo〉.

\section{Coleta e análise dos dados}

Os dados foram coletados através de um questionário que se encontrava em anexo ao final de cada um dos hipertextos digitais elaborados como materiais prévios para as aulas invertidas, composto sempre pelas mesmas cinco perguntas (apresentadas nos resultados), em cada hipertexto, a fim de analisar as percepções dos acadêmicos quanto a forma e dificuldades de acesso, dificuldades de estudo, qual item do hipertexto mais ajudou e sua adequação.

A análise das perguntas fechadas foi realizada por meio dos escores das respostas, enquanto a análise das perguntas abertas foi através da análise de conteúdo, com base em Bardin (2011), optando-se pela análise classificatória categorial, a qual "pretende tomar em consideração a totalidade de um texto, passando-o pelo crivo da classificação e do recenseamento, segundo a frequência de presença (ou de ausência) de itens de sentido" (Bardin, 1977, p. 36).

Por meio da análise de conteúdo é possível realizar a descrição da essência de mensagens e suas inferências relacionadas (Bardin, 2011), sendo a construção das categorias, neste estudo, feita a posteriori, ou seja, realizada a partir das respostas dos participantes, e o corpus (material analisado) composto pelas perguntas e respostas.

\section{Resultados e discussão}

Os acadêmicos participantes deste estudo pertenciam a diversos cursos da área da saúde, como Biomedicina, Ciências Biológicas, Educação Física, Estética e Cosmética, Farmácia, Fisioterapia e Fonoaudiologia.

A análise das perguntas fechadas foi apresentada em forma de gráficos, enquanto as perguntas abertas, por meio de quadros, as quais requeriam justificativas. Optou-se por apresentar os dados de forma separada para cada aula invertida, a fim de estabelecer comparações entre elas e aproveitar o detalhamento proporcionado por este tipo de análise. Essa estratégia de investigar as percepções dos alunos pode auxiliar os docentes a entender pelo que os estudantes mais se interessaram, acharam mais novo ou sentiram maior dificuldade. De posse dessas informações é possível organizar estratégias presenciais que ajudem os discentes a superar suas dificuldades de aprendizagem (Martin et al., 2018). 
Na primeira pergunta objetiva os alunos foram solicitados a responder de que forma acessaram o estudo prévio, se "Em um telefone celular", "Em um computador em casa" ou "Em um computador na faculdade e/ou outro local". Na Figura 2 é possível verificar as porcentagens das respostas para todas as aulas invertidas realizadas, por semestre:

Figura 2: Forma de acesso aos estudos prévios

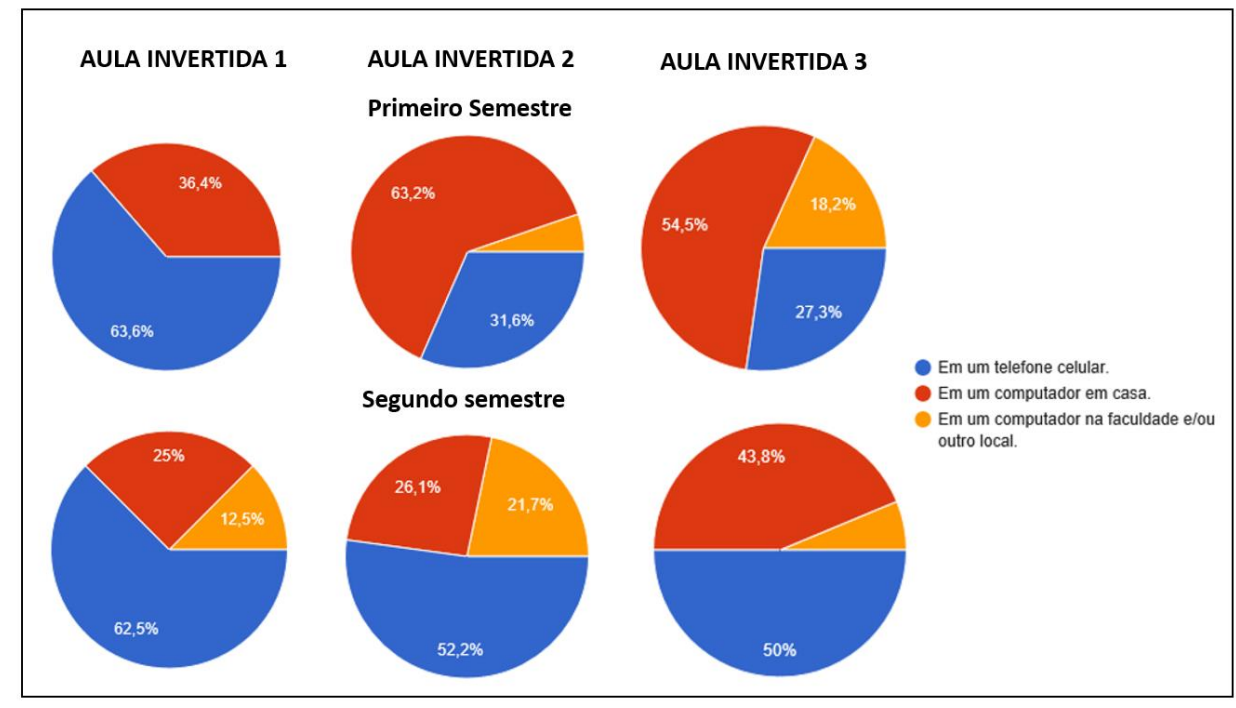

Fonte: Os autores (2020)

Percebe-se, com base na Figura 2, que o percentual foi variado no decorrer das aulas invertidas, mas que houve predomínio do acesso por telefone celular em quatro dos seis estudos prévios, enquanto nos outros dois a maior porcentagem foi para o estudo em casa por meio de computador. Estes dados são condizentes com o contexto digital atual, especialmente entre o público jovem, apontam a relevância das tecnologias móveis e chamam a atenção para que o professor proporcione materiais prévios que possam ser acessados via celular, tendo cuidado em evitar plataformas que não possibilitam este acesso.

Lucena (2016) comenta que o público que mais utiliza as tecnologias móveis são jovens entre 16 e 24 anos, ou seja, aqueles que frequentam os ambientes de ensino; por meio do uso de tablets, notebooks e smartphones têm se intensificado as comunicações desprendidas de lugares fixos, já que estes dispositivos podem ser carregados para qualquer lugar. Assim, a imersão em um ambiente tecnológico faz parte da realidade cotidiana, adquirindo importância também nos processos educativos, facilitando o compartilhamento de atividades (Infante \& Velásquez, 2018).

Este dado de maior acesso ao estudo prévio via telefone celular, acrescentado ao acesso em outros locais (como na faculdade), embora em menor porcentagem, vem ao 
encontro dos pressupostos de modalidades híbridas como a SAI, que se referem ao controle do acesso, ritmo e local de estudo pelos alunos (Christensen, Horn \& Staker, 2013) nas atividades de pré-aula e apontam que, nesta pesquisa, este aspecto foi contemplado.

$\mathrm{Na}$ segunda pergunta objetiva os alunos precisavam marcar uma das opções referentes a problemas de acesso ao material de pré-aula, sendo elas: "Não teve absolutamente nenhum problema para acessar o material", "Teve problemas, mas nada que prejudicasse o estudo", e "Teve problemas de acesso que comprometeram o estudo". Na Figura 3 é possível observar as porcentagens das respostas dos alunos, organizadas por aula invertida e semestre.

Figura 3: Dificuldade de acesso aos materiais prévios da SAI

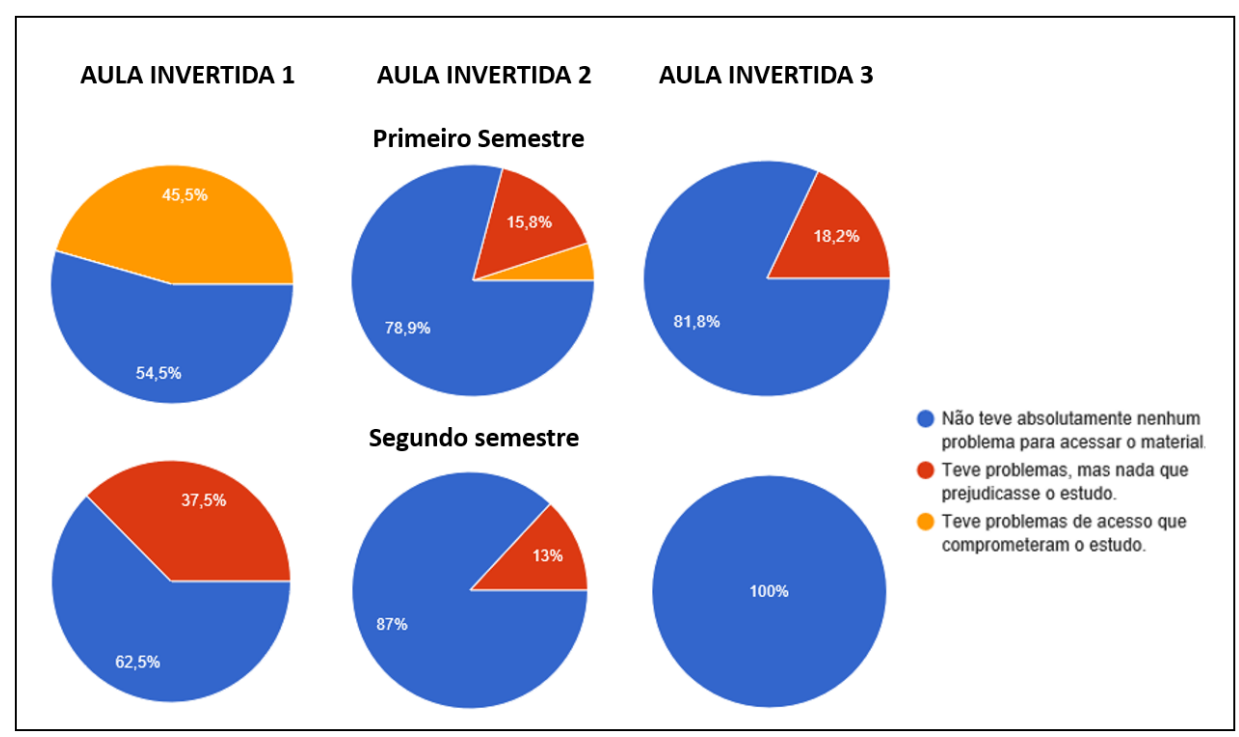

Fonte: Os autores (2020)

A Figura 3 mostra que prevaleceu com maior percentual, em todas as aulas invertidas, a opção "Não teve absolutamente nenhum problema para acessar o material", inclusive, na terceira aula invertida do segundo semestre, esta opção foi unânime entre os participantes. A partir desta constatação é possível inferir que, apesar de alguns problemas pontuais apontados, principalmente na aula invertida número 1 (45,5\%), predominou a inexistência de maiores problemas quanto ao acesso.

Para entender melhor sobre as dificuldades dos alunos no estudo prévio por meio dos hipertextos digitais, foi aplicada a pergunta: "Você encontrou alguma dificuldade em estudar por meio deste material? Se sim, quais?", cujas respostas estão categorizadas no Quadro 1: 
Quadro 1: Dificuldades de estudo nos materiais pré-aula

\begin{tabular}{|c|c|c|c|c|}
\hline Categoria & $\begin{array}{c}\text { Subcategorias } \\
\text { primárias }\end{array}$ & Subcategorias secundárias & $\mathbf{f}$ & \% Respostas \\
\hline \multicolumn{5}{|c|}{ Primeiro semestre } \\
\hline \multicolumn{5}{|c|}{ Aula Invertida 1 - Sistema muscular } \\
\hline \multirow{5}{*}{$\begin{array}{l}\text { Dificuldad } \\
\text { es de } \\
\text { estudo no } \\
\text { material } \\
\text { pré-aula }\end{array}$} & \multirow[t]{3}{*}{ Sim } & Pouco tempo de estudo & 2 & 20 \\
\hline & & Abrir os vídeos & 1 & 10 \\
\hline & & Problemas de conexão & 1 & 10 \\
\hline & Não & - & 4 & 40 \\
\hline & Sem resposta & & 2 & 20 \\
\hline Total & & & 10 & 100 \\
\hline \multicolumn{5}{|c|}{ Aula Invertida 2 - Sistema circulatório } \\
\hline \multirow{7}{*}{$\begin{array}{l}\text { Dificuldad } \\
\text { es de } \\
\text { estudo no } \\
\text { material } \\
\text { pré-aula }\end{array}$} & Não & - & 12 & 67,0 \\
\hline & \multirow[t]{5}{*}{ Sim } & Falta de exposição docente & 1 & 5,5 \\
\hline & & $\begin{array}{l}\text { Dificuldade de entendimento/tema } \\
\text { complexo }\end{array}$ & 1 & 5,5 \\
\hline & & Falta de correção no momento & 1 & 5,5 \\
\hline & & Abrir os vídeos & 1 & 5,5 \\
\hline & & Como aprender pequenos detalhes & 1 & 5,5 \\
\hline & Sem resposta & & 1 & 5,5 \\
\hline Total & & & 18 & 100 \\
\hline \multicolumn{5}{|c|}{ Aula Invertida 3 - Sistema genital/urinário } \\
\hline \multirow{3}{*}{$\begin{array}{l}\text { Dificuldad } \\
\text { es de } \\
\text { estudo no } \\
\text { material } \\
\text { pré-aula }\end{array}$} & Não & - & 9 & 81,8 \\
\hline & Sim & Abrir o material & 1 & 9,1 \\
\hline & Sem resposta & - & 1 & 9,1 \\
\hline Total & & & 11 & 100 \\
\hline \multicolumn{5}{|c|}{ Segundo semestre } \\
\hline \multicolumn{5}{|c|}{ Aula Invertida 1 - Sistema circulatório } \\
\hline \multirow{3}{*}{$\begin{array}{l}\text { Dificuldad } \\
\text { es de } \\
\text { estudo no } \\
\text { material } \\
\text { pré-aula }\end{array}$} & Não & - & 14 & 87,6 \\
\hline & \multirow[t]{2}{*}{ Sim } & Memorizar o conteúdo & 1 & 6,2 \\
\hline & & $\begin{array}{l}\text { Problemas com a plataforma de acesso } \\
\text { ao link }\end{array}$ & 1 & 6,2 \\
\hline Total & & & 16 & 100 \\
\hline \multicolumn{5}{|c|}{ Aula Invertida 2 - Sistema respiratório } \\
\hline \multirow{3}{*}{$\begin{array}{l}\text { Dificuldad } \\
\text { es de } \\
\text { estudo no } \\
\text { material } \\
\text { pré-aula }\end{array}$} & Não & - & 19 & 90,4 \\
\hline & \multirow[t]{2}{*}{ Sim } & Encontrar o material & 1 & 4,8 \\
\hline & & Esquema dinâmico & 1 & 4,8 \\
\hline Total & & & 21 & 100 \\
\hline \multicolumn{5}{|c|}{ Aula Invertida 3 - Sistema genital/urinário } \\
\hline $\begin{array}{l}\text { Dificuldad } \\
\text { es de } \\
\text { estudo no } \\
\text { material } \\
\text { pré-aula }\end{array}$ & Não & - & 16 & 100 \\
\hline Total & & & 16 & 100 \\
\hline
\end{tabular}


Entende-se, com base no Quadro 1, que com o passar das aulas a dificuldade de estudo dos acadêmicos nos hipertextos digitais vai diminuindo, sendo as duas últimas aulas invertidas (segundo semestre) as que menos apontaram dificuldades, pelo que se infere dois pontos: o primeiro, os alunos passam a se familiarizar ao novo formato de aula e aperfeiçoam o estudo prévio; o segundo, o professor vai adquirindo habilidades no desenvolvimento dos materiais pré-aula, melhorando crescentemente o que disponibiliza para estudo prévio. Este dado é importante, pois mostra que os docentes não devem se frustrar com uma primeira tentativa não exitosa de aula-invertida, uma vez que sua ambientação pelos estudantes ocorre de forma processual.

Observa-se, ainda, que o número de respostas ao material pré-aula foi maior nos dois semestres, na segunda aula invertida. Entre as maiores dificuldades apontadas pelos alunos nos estudos prévios para as aulas invertidas a mais expressiva foi "Pouco tempo de estudo", o que pode estar relacionado com o perfil do público da pesquisa, em sua maioria trabalhadores, que dividem seu tempo entre atividade laboral e estudo.

É possível dividir as dificuldades apresentadas pelos participantes na pré-aula em dois grupos: relacionadas com o suporte técnico e relacionadas com a didática metodológica. "Problemas de conexão", “Abrir os vídeos”, "Abrir o material”, "Problemas com a plataforma" expressam dificuldades relacionadas ao componente técnico. "Pouco tempo de estudo", "Falta de exposição docente", "Dificuldade de entendimento", "Falta de correção no momento", entre outras, expressam dificuldades relacionadas com a metodologia.

As dificuldades referentes a metodologia vão ao encontro, principalmente, da falta de exposição docente e da dificuldade que os alunos têm de desenvolver um estudo autônomo. Respostas dos alunos corroboram:

Dificuldade não, mas é ótimo quando se tem a explicação do professor pessoalmente, o conteúdo é mais absorvido (Aluno 16, aula invertida 1 do segundo semestre).

Sim, mas complicado estudar, algumas pessoas, como eu, entendem melhor com o conteúdo sendo explicado (Aluno 9, aula invertida 2 do primeiro semestre).

Cabe considerar que, de fato, as pessoas aprendem de formas diferentes, e uma delas pode ser ouvindo a explicação do professor; no entanto, também é pertinente destacar que no contexto atual os acadêmicos ainda são demasiadamente dependentes da aula expositiva e têm dificuldades de estudo, em função do seu pouco hábito metacognitivo e 
autorregulador de suas aprendizagens, para com os quais a sala de aula invertida tem potencial de contribuir.

Martins et al. (2019) verificaram em sua pesquisa que os alunos, por não estarem acostumados com a sala de aula invertida, não realizam da forma devida as atividades prévias, pois não estão preparados para assumirem sua autorregulação, já que isso não lhes é familiar, visto que sua formação até o momento foi pelo método tradicional. No entanto, como salienta Moran (2012, p. 33), "aprender depende também do aluno, de que ele esteja pronto, maduro, para incorporar a real significação que a informação tem para ele [..]".

Para Bergmann e Sams (2018), um dos inconvenientes da sala de aula invertida é de que os alunos não podem fazer de imediato as perguntas no estudo prévio, como seria em uma aula presencial. Por isso, é importante que recebam dicas de como realizá-lo, anotando, resumindo e transcrevendo pontos importantes e as dúvidas a serem perguntadas posteriormente, o que os ajuda nesta etapa.

A respeito do material pré-aula, os alunos foram questionados sobre qual componente dos hipertextos digitais disponibilizados para estudo prévio mais os auxiliaram na aprendizagem do conteúdo. As porcentagens das respostas são apresentadas na Figura 4:

Figura 4: Componente dos hipertextos digitais que mais auxiliou para a aprendizagem

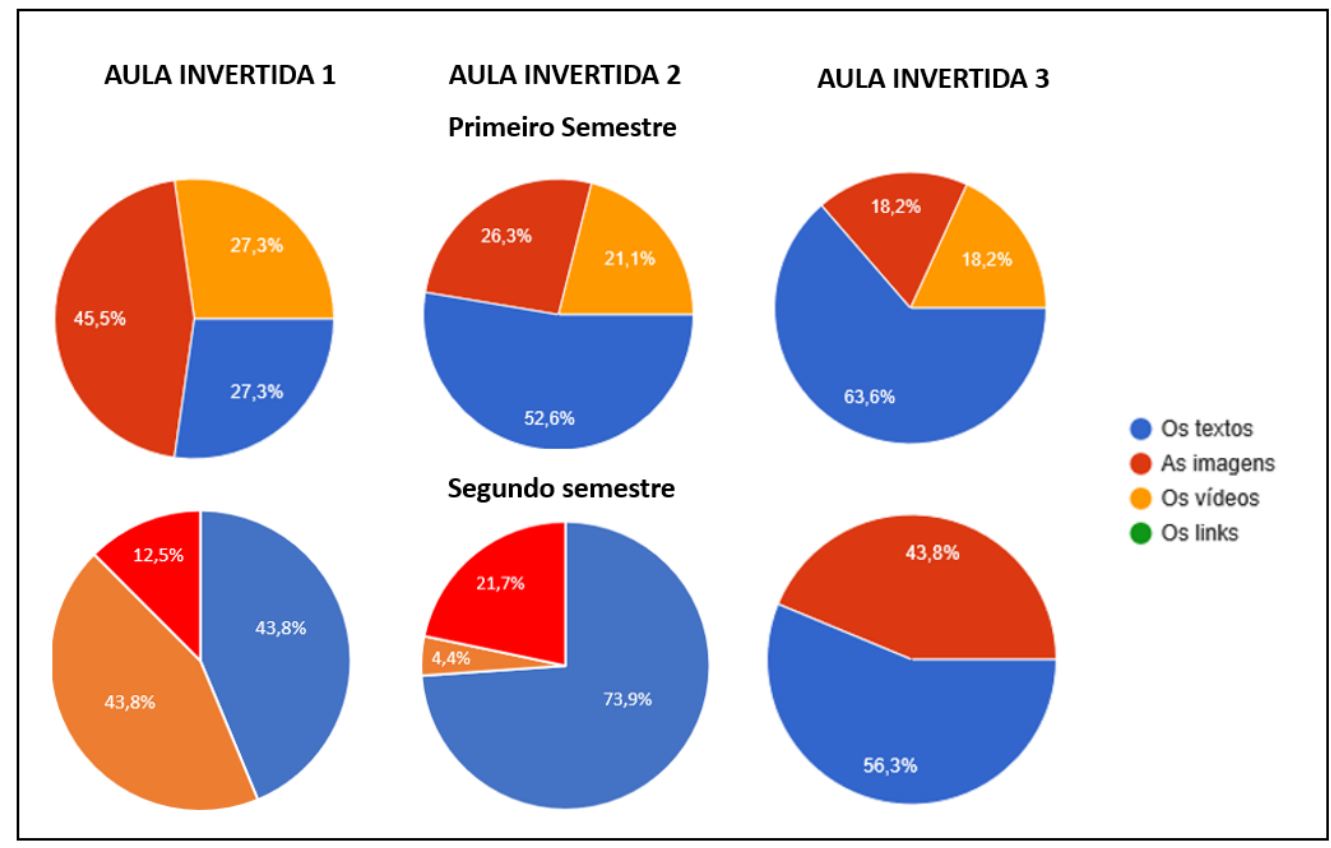

Fonte: Os autores (2020)

As porcentagens de respostas para esta pergunta apresentaram-se, para quatro delas, com predominância de preferência pelos textos como de maior auxílio da aprendizagem 
pré-aula, o que demonstra que os alunos ainda estão mais restritos aos textos escritos como fonte primária das informações. Os vídeos apareceram com uma porcentagem expressiva na primeira aula invertida do segundo semestre e as imagens em duas ocasiões, na primeira aula do primeiro semestre e na terceira aula do segundo semestre; sendo assim, as imagens apresentam-se como o segundo elemento de maior relevância pelos alunos nos hipertextos digitais e os vídeos, como terceiro elemento mais importante.

Os links, por sua vez, foram desconsiderados pelos alunos como importantes para seu estudo. No entanto, cabe considerar que eles exercem um papel importante no esclarecimento de termos. Na pesquisa de Júnior e Martins (2019), sobre leitura em hipertexto digital, $23 \%$ dos participantes disseram localizar o link, mas preferiram não acessá-los; já 27\% nem localizou-os no texto, somando um percentual de metade dos participantes que leram o hipertexto sem acessar os links; para os autores, o não acesso aos links pode prejudicar a compreensão global do texto, embora o leitor tenha autonomia para decidir seu percurso hipertextual.

Para Santos, Moser e Lima (2019), há um diálogo entre os próprios elementos hipertextuais que se remetem, auxiliando na compreensão do que ele está expondo, somada à coprodução do leitor, que deve ser ativo, construtivo, e requer uma leitura diferente de um texto linear. Diante de um hipertexto digital o discente possui duas alternativas de ação, que é a passividade ou a atividade; para que haja interatividade o aluno dever seguir as trilhas propostas pelo hipertexto, conforme seu ritmo de estudo.

Pinheiro e Araújo (2016) abordam a questão do letramento hipertextual, que se configura pelo entrelaçamento de outros letramentos, como o tecnológico, o digital e o comunicacional; isso porque a compreensão dos sentidos, por vezes, só ocorre se o usuário conseguir mobilizar mais de um letramento, sendo assim algo complexo.

Os alunos foram questionados sobre a adequação do material prévio (hipertextos digitais) para o estudo pré-aula. Para uma melhor organização dos dados, as respostas para esta pergunta foram categorizadas em dois quadros, um para o primeiro semestre e outro para o segundo semestre. No Quadro 2 apresenta-se a categorização para os dados referentes ao primeiro semestre: 
Quadro 2 - Adequação do material de pré-aula (hipertextos digitais), primeiro semestre

\begin{tabular}{|c|c|c|c|c|}
\hline Categoria & $\begin{array}{c}\text { Subcategorias } \\
\text { primárias }\end{array}$ & Subcategorias secundárias & $\mathbf{f}$ & \% Respostas \\
\hline \multicolumn{5}{|c|}{ Primeiro semestre } \\
\hline \multicolumn{5}{|c|}{ Aula Invertida 1 - Sistema muscular } \\
\hline \multirow{7}{*}{$\begin{array}{c}\text { Adequação } \\
\text { do material } \\
\text { prévio }\end{array}$} & \multirow[t]{6}{*}{ Sim } & Completo/exemplificado & 3 & 30 \\
\hline & & Sem justificativa & 2 & 20 \\
\hline & & Simples e objetivo & 1 & 10 \\
\hline & & Poderia ter mais imagens & 1 & 10 \\
\hline & & Poderia ser postado antes & 1 & 10 \\
\hline & & Falta de explicação docente & 1 & 10 \\
\hline & Sem resposta & - & 1 & 10 \\
\hline Total & & & 10 & 100 \\
\hline \multicolumn{5}{|c|}{ Aula Invertida 2 - Sistema circulatório } \\
\hline \multirow{9}{*}{$\begin{array}{c}\text { Adequação } \\
\text { do material } \\
\text { prévio }\end{array}$} & \multirow[t]{8}{*}{ Sim } & Sem justificativa & 5 & 27,9 \\
\hline & & $\begin{array}{l}\text { Ajudou no entendimento da matéria } \\
\text { proposta/preparação para aula presencial }\end{array}$ & 4 & 22,4 \\
\hline & & Completo/dinâmico/informativo & 3 & 16,7 \\
\hline & & Ilustrativo, fácil entendimento & 1 & 5,5 \\
\hline & & De grande ajuda, mas confuso & 1 & 5,5 \\
\hline & & $\begin{array}{l}\text { Material explícito, com imagens e } \\
\text { exemplos interessantes }\end{array}$ & 1 & 5,5 \\
\hline & & Poderia ter mais vídeos & 1 & 5,5 \\
\hline & & Prefiro explicação & 1 & 5,5 \\
\hline & Sem resposta & & 1 & 5,5 \\
\hline Total & & & 18 & 100 \\
\hline \multicolumn{5}{|c|}{ Aula Invertida 3 - Sistema genital/urinário } \\
\hline \multirow{8}{*}{$\begin{array}{c}\text { Adequação } \\
\text { do material } \\
\text { prévio }\end{array}$} & \multirow[t]{7}{*}{ Sim } & Didático/fácil compreensão & 2 & 18,3 \\
\hline & & $\begin{array}{l}\text { Contém todas as informações } \\
\text { necessárias }\end{array}$ & 2 & 18,3 \\
\hline & & Explicativo/específico e adequado & 2 & 18,3 \\
\hline & & Ótima qualidade, entendimento & 1 & 9,0 \\
\hline & & Continha textos, imagens e vídeos & 1 & 9,0 \\
\hline & & Poderia ter mais vídeos & 1 & 9,0 \\
\hline & & Sem justificativa & 1 & 9,0 \\
\hline & Sem resposta & - & 1 & 9,0 \\
\hline Total & & & 11 & 100 \\
\hline
\end{tabular}

Para este questionamento se observou que a expressiva maioria dos acadêmicos concordam que os materiais elaborados (hipertextos digitais) estavam adequados para o estudo prévio. Justificativas de destaque dos alunos foi quanto ao material estar completo e de fácil compreensão, o que pode ser observado nas subcategorias secundárias "Completo/exemplificado" e "Completo/dinâmico/informativo", da primeira e segunda aula invertida, respectivamente. As respostas dos alunos corroboram:

Sim, o material de texto de ótima qualidade, de fácil entendimento, muito claro e direto, as imagens e os vídeos ajudaram muito para obter uma noção de localização de cada estrutura (aluno 3, aula invertida 3 do primeiro semestre). 
Todos os materiais publicados na plataforma net aula estão super elaborados e de formas super específicas, com tópicos muito bem adequados para o tema tratado (aluno 10, aula invertida 3 do primeiro semestre).

Isso aponta para a relevância em organizar um material que contenha todas as informações necessárias para o estudo em questão, que elas sirvam de suporte e que de posse delas os alunos tenham condições de acompanhamento das atividades presenciais posteriores. Santos, Moser e Lima (2019) constataram em sua pesquisa que o hipertexto digital pode se constituir um mediador para a aprendizagem, um poderoso auxílio para os docentes, que ajuda na aprendizagem ativa, e deve ser elaborado considerando a carga cognitiva dos discentes.

No Quadro 3 apresenta-se a categorização para os dados referentes ao segundo semestre, para a mesma pergunta, sobre a adequação do material prévio (hipertextos digitais) para o estudo pré-aula:

Quadro 3: Adequação do material de pré-aula (hipertextos digitais), segundo semestre

\begin{tabular}{|c|c|c|c|c|}
\hline Categoria & $\begin{array}{c}\text { Subcategorias } \\
\text { primárias }\end{array}$ & Subcategorias secundárias & $\mathbf{f}$ & $\begin{array}{c}\% \\
\text { Respostas }\end{array}$ \\
\hline \multicolumn{5}{|c|}{ Segundo semestre } \\
\hline \multicolumn{5}{|c|}{ Aula Invertida 1 - Sistema circulatório } \\
\hline \multirow{9}{*}{$\begin{array}{l}\text { Adequação do } \\
\text { material prévio }\end{array}$} & \multirow[t]{8}{*}{ Sim } & Material completo/Fácil compreensão & 4 & 25,0 \\
\hline & & Explicativo & 3 & 18,7 \\
\hline & & Claro/objetivo/exemplificado & 2 & 12,5 \\
\hline & & Sem justificativa & 2 & 12,5 \\
\hline & & Linguagem simples e direta & 1 & 6,2 \\
\hline & & Resumido e especificado & 1 & 6,2 \\
\hline & & Didático/chamativo & 1 & 6,2 \\
\hline & & Apresentou noções sobre o sistema & 1 & 6,2 \\
\hline & \multirow[t]{2}{*}{ Não } & Cansativo e longo & 1 & 6,2 \\
\hline Total & & & 16 & 100 \\
\hline \multicolumn{5}{|c|}{ Aula Invertida 2 -Sistema respiratório } \\
\hline \multirow{9}{*}{$\begin{array}{l}\text { Adequação do } \\
\text { material prévio }\end{array}$} & \multirow[t]{9}{*}{ Sim } & Fácil entendimento/explicativo & 5 & 23,9 \\
\hline & & Completo/dinâmico & 5 & 23,9 \\
\hline & & Sem justificativa & 3 & 14,2 \\
\hline & & Claro/objetivo/fácil acesso & 2 & 9,6 \\
\hline & & Resumido e importante & 2 & 9,6 \\
\hline & & Exemplificado & 1 & 4,7 \\
\hline & & Adequado e didático & 1 & 4,7 \\
\hline & & Trouxe bastante conhecimento & 1 & 4,7 \\
\hline & & Traz ideia do que será estudado & 1 & 4,7 \\
\hline Total & & & 21 & 100 \\
\hline \multicolumn{5}{|c|}{ Aula Invertida 3 - Sistema genital/urinário } \\
\hline \multirow{4}{*}{$\begin{array}{l}\text { Adequação do } \\
\text { material prévio }\end{array}$} & \multirow[t]{4}{*}{ Sim } & Fácil compreensão/acessível/simples & 5 & 31,2 \\
\hline & & Sem justificativa & 3 & 18,7 \\
\hline & & Conteúdo completo/bom entendimento & 3 & 18,7 \\
\hline & & Adequado e bem explicado & 2 & 12,6 \\
\hline
\end{tabular}




\begin{tabular}{|c|c|c|c|c|}
\hline \multirow{2}{*}{} & \multirow{2}{*}{ Total } & Claro e objetivo & 2 & 12,6 \\
\cline { 3 - 4 } & & Postado com antecedência & 1 & 6,2 \\
\hline & & & 16 & 100 \\
\hline
\end{tabular}

As respostas do segundo semestre para esta questão apresentaram uma concordância ainda maior, principalmente nas justificativas dos alunos, sendo a subcategoria secundária de maior frequência relacionada ao mesmo aspecto nas três aplicações, referindo-se ao material como de fácil entendimento: "Material completo/fácil compreensão", "Fácil entendimento/explicativo", "Fácil compreensão/acessível/simples". Na pesquisa de Bandeira-Scheunemann e Lopes (2018), o hipertexto digital se apresentou como um recurso favorável à aprendizagem discente, destacado pelos alunos como auxiliar no aprofundamento do tema estudado, além de ressaltarem o recurso como motivador, interessante e de fácil acesso, entre outros aspectos.

Nazário et al. (2020) comentam a respeito dos desafios que a metodologia da SAI apresenta para os docentes e discentes, pois requer mudanças a processos já estabelecidos e consolidados; para o autor, a escolha e elaboração de materiais claros e objetivos é fundamental para garantir o bom desempenho dos alunos.

Para Talbet (2019), a SAI pode ser o futuro do ensino superior, o que à coloca em uma posição de destaque, para a qual se deve dedicar tempo, atenção e esforços; a adoção desta metodologia requer um conjunto de recursos e uma comunidade que auxilie no compartilhamento de sua prática.

Desse modo, investigar os materiais de estudo prévio, como os hipertextos digitais, é um caminho necessário para o aprimoramento das práticas de SAI, a fim de proporcionar novas perspectivas de atividades e materiais a serem utilizados e que possam contribuir para a eficácia da metodologia e o melhoramento da sua aplicação.

\section{Considerações finais}

Este estudo teve como objetivo investigar as percepções de acadêmicos da área da saúde sobre a utilização de hipertextos digitais como material de estudo prévio na sala de aula invertida e sugeri-los como possibilidade de material didático prévio para esta metodologia.

A partir do estudo desenvolvido por meio da aplicação de seis aulas invertidas distribuídas em dois semestres, algumas considerações podem ser estabelecidas. No que se refere a forma de acesso aos hipertextos digitais, em quatro das seis aulas predominou a 
utilização de telefone celular, indo ao encontro da mobilidade observada na contemporaneidade e seu uso pelo público jovem.

Quanto a dificuldades de acesso aos hipertextos digitais, a maioria dos alunos não apresentou maiores problemas; quanto a dificuldades de estudo por meio dos hipertextos digitais, foram mais evidenciadas nas primeiras aulas invertidas e se dividiram em dois grupos principais, as dificuldades de conexão (técnica) e as dificuldades relacionadas com a didática (metodológica).

Sobre o componente dos hipertextos que mais ajudou no estudo, em quatro das seis aulas invertidas sobressaíram os textos; as imagens apresentam-se como o segundo elemento de maior relevância pelos alunos nos hipertextos digitais e os vídeos, como terceiro elemento mais importante. Ainda, quando questionados sobre a adequação dos materiais, a maioria dos acadêmicos concordaram que os hipertextos digitais estavam adequados para o estudo prévio, especialmente por serem completos e de fácil compreensão.

Embora com limitações, como o tamanho amostral, este estudo oferece uma sugestão de material didático para a aula prévia na metodologia da sala de aula invertida, por meio de hipertextos digitais, e colabora com a literatura para o entendimento de percepções de acadêmicos sobre este recurso para estudo na pré-aula no ensino de anatomia humana, que apresenta estudos ainda incipientes quanto a esta temática.

Pretende-se, como continuação desta pesquisa, investigar outras questões relativas à aula invertida, como o engajamento dos alunos nas aulas prévias e atividades presenciais para esta metodologia no ensino e aprendizagem de anatomia humana.

\section{Agradecimentos e apoios}

O presente trabalho foi realizado com apoio da Coordenação de Aperfeiçoamento de Pessoal de Nível Superior - Brasil (CAPES) - Código de Financiamento 001.

\section{Referências}

Bandeira-Scheunemann, C. M. \& Lopes, P. T. C. (2018). Análise de um hipertexto digital no ensino de ciências: percepções de alunos do Ensino Fundamental. REnCiMa Revista de Ensino de Ciências e Matemática, 9(5), 14-35.

Bardin, L. (1977). Análise de conteúdo. Edições 70.

Bardin, L. (2011). Análise de conteúdo. Edições 70. 
Bergmann, J. \& Sams, A. (2012). Flip your classroom: reach every student in every class every day. ISTE.

Bergmann, J. \& Sams, A. (2014). Flipped learning: gateway to student engagement. ISTE.

Bergmann, J. \& Sams, A. (2018). Sala de Aula Invertida: uma metodologia ativa de aprendizagem. LTC.

Bergmann, J. (2018). Aprendizagem invertida para resolver o problema do dever de casa. Penso.

Carvalho, M. A. V., Fornaziero, C. C., Tonani, E. C. F. \& Valle, T. S. (2012). Transformaciones en la escena de la educación presencial: la inserción de tecnologias. Paradigma, 33(2), 89-100.

Christensen, C. M., Horn, M. B. \& Staker, H. (2013). Is K-12 Blended Learning Disruptive? An introduction to the theory of hybrids. Clayton Christensen Institute.

Conserva, D. P. \& Costa, M. A. M. (2020). O ensino de inglês permeado pela proposta de sala de aula invertida: um relato de experiência didática. Educação Temática Digital, 22(1), 234-252.

Fonseca, J. J. S. (2002). Metodologia da pesquisa científica. UEC. Apostila.

Godoy, A. S. (2006). Estudo de caso qualitativo. Em: C. K. Godoi, R. Bandeira de Melo e A. B. Silva, Pesquisa qualitativa em estudos organizacionais: paradigmas, estratégias e métodos. Saraiva.

González-Gómez, D., Jeong, J. S., Cañada-Cañada, F. \& Picó, A. G. (2017). Enseñanza de contenidos científicos a través de un modelo "Flipped": propuesta de instrucción para estudiantes del grado de educación primária. Enseñanza de las Ciências, 35(2), 71-87.

Infante, E. M. \& Velásquez, F. R. (2018). Visión profesional sobre el uso de las TIC en la praxis educativa, desde la perspectiva de los estudiantes de ciencias pedagógicas. Paradigma, 39(1), 229-245.

Jensen, J. L., Holt, E. A., Sowards, J. B., Ogden, T. H. \& West, R. E. (2018). Investigating Strategies for Pre-Class Content Learning in a Flipped Classroom. Journal of Science Education and Technology, 27, 523-535.

Júnior, J. R. C. \& Martins, S. N. (2019). A percepção dos alunos sobre o uso de webquest no desenvolvimento da leitura hipertextual. Revista Exitus, 9(2), 351 - 380.

Kirschbaum, C. (2013). Decisões entre pesquisas quali e quanti sob a perspectiva de mecanismos causais. Revista Brasileira de Ciências Sociais, 28(82).

Lévy, P. (1993). As tecnologias da inteligência. Editora 34.

Lucena, S. (2016). Culturas digitais e tecnologias móveis na educação. Educar em Revista, $59,277-290$.

Martin, A. P., Martin, D. D., Aguilera, I. D., Sanz, J. M., Torner, P. S., Campión. R. S., Almuzara, A. C. \& Soto, M. A. M. (2018). Nuevas combinaciones de aula inversa con just in time teaching y análisis de respuestas de alumnos. Revista Iberoamericana de Educación a Distancia, 21(1), 175-194.

Martins, E. R., Gouveia, L. M. B., Afonseca, U. R. \& Geraldes, W. B. (2019). Comparação entre o modelo da sala de aula invertida e o modelo tradicional no ensino de matemática na perspectiva dos aprendizes. Experiências em Ensino de Ciências, 14(1), $522-530$. 
Moran, J. M. (2012). A educação que desejamos: novos desafios e como chegar lá. $5^{a}$ ed. Papirus.Nazário, A. A., Lopes, B. J. S., Carvalho, W. A. F. \& Fernandes, L. M. (2020). Sala de Aula Invertida: uma experiência com alunos veteranos no curso de engenharia agronômica. Laplage em Revista, 6(1), 129-140.

Pavanelo, E. \& Lima, E. (2017). Sala de aula invertida: a análise de uma experiência na disciplina de Cálculo I. Bolema: Boletim de Educação Matemática, 31(58), 739-759.

Pinheiro, R. C. \& Araújo, J. C. (2016). Letramento hipertextual: um amálgama de letramentos demandados em cursos online. Trabalhos em Linguística Aplicada, 55(2), 401-430.

Ribeirinha, T. \& Silva, B. D. (2020). Avaliando a eficácia da componente online da "Sala de Aula Invertida:" um estudo de investigação-ação, Revista e-Curriculum, 18(2), 568-589.

Sánchez-Rodríguez, J.; Palmero, J. R. \& Veja, E. S. (2017). Flipped Classroom. Claves para su puesta en práctica. EDMETIC: Revista de Educación Mediática y TIC, 6(2), 336-358.

Santana, M. O. de S. \& Aragão, R. C. (2013). O hipertexto e a multimodalidade em práticas textuais com blog no ensino de línguas. Hipertextus Revista Digital, 10, 1-21.

Santos, R. O., Moser, A. \& Lima, T. (2019). Hipertexto como mediador pedagógico. Revista Diálogo Educacional, 19(61), 792-808.

Sommer, M. \& Ritzhaupt, A. (2018). Impact of the Flipped Classroom on learner achievment and satisfaction in an undergraduate Technology Litracy Course. Journal of Information Technology Education, 17, 159-182.

Stake, R. E. (2000). Case studies. In: N. K. Denzin \& Y. S. Lincoln (Eds.), Handbook of qualitative research (pp. 435-453). SAGE.

Talbert, R. (2019). Guia para a utilização da aprendizagem invertida no ensino superior. Penso.

Valente, J. A. (2014). Blended learning e as mudanças no ensino superior: a proposta da sala de aula invertida. Educar em Revista, Edição Especial (4), 79-97.

Valente, J. A. (2018). A Sala de Aula Invertida e a Possibilidade do Ensino Personalizado: uma experiência com a graduação em Midialogia. Em: L. Bacich \& J. Moran (Org.). Metodologias ativas para uma educação inovadora: uma abordagem técnoco-prática (pp. 26-44). Penso.

Valério, M. \& Moreira, A. L. O. R. (2018). Sete críticas à sala de aula invertida. Contexto \& Educação, 33(106), 215-230.

Yang, C. C. R. (2017). An investigation of the use of the "Flipped Classroom" pedagogy in secondary english lenguage classrooms. Journal of Information Technology Education, 16, 1-20.

Autores

Camila Maria Bandeira Scheunemann

Mestre em Ensino de Ciências e Matemática pela Universidade Luterana do Brasil (2018). Doutoranda em Ensino de Ciências e Matemática pela Universidade Luterana do Brasil.

E-mail: camila.b91@ @otmail.com 
Caroline Medeiros Martins de Almeida Doutora em Ensino de Ciências e Matemática pela Universidade Luterana do Brasil com período sanduíche pelo PDSE/CAPES na Universidade do Porto - Portugal (2018). PósDoutorado pelo PNPD/CAPES junto ao Programa de Pós-Graduação em Ensino de Ciências e Matemática pela Universidade Luterana do Brasil. Atualmente é professora pesquisadora do Programa de Pós-Graduação em Gestão Educacional na Universidade do Vale do Rio dos Sinos, integrando a linha de pesquisa Gestão Escolar e Universitária. Participa do setor da Formação Docente, no Núcleo de Inovação, Avaliação e Formação NIAF na UNISINOS. E-mail: carolinemalmeida@ unisinos.br 